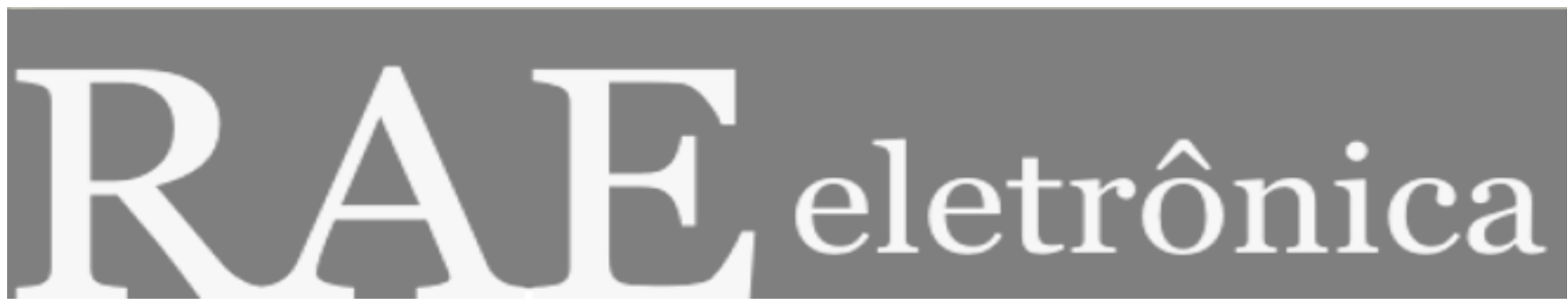

\title{
GESTÃO DA MATURIDADE DE PROCESSOS ESSENCIAIS - CONVERGÊNCIA PARA O FUTURO
}

Por:

Leandro Rosa dos Santos

RAE-eletrônica, Volume 2, Número 1, jan-jun/2003.

http://www.rae.com.br/eletronica/index.cfm?FuseAction=Artigo \&ID $=1863 \&$ Secao $=2^{\circ} \mathrm{PWC} \&$ Volume $=2 \&$ Numero $=1 \&$ Ano $=2003$

CCopyright, 2002, RAE-eletrônica. Todos os direitos, inclusive de tradução, são reservados. É permitido citar parte de artigos sem autorização prévia desde que seja identificada a fonte. A reprodução total de artigos é proibida. Os artigos só devem ser usados para uso pessoal e nãocomercial. Em caso de dúvidas, consulte a redação: redacao@rae.com.br.

A RAE-eletrônica é a revista on-line da FGV-EAESP, totalmente aberta e criada com o objetivo de agilizar a veiculação de trabalhos inéditos. Lançada em janeiro de 2002, com perfil acadêmico, é dedicada a professores, pesquisadores e estudantes. Para mais informações consulte o site www.rae.com.br/eletronica.

RAE-eletrônica

ISSN 1676-5648

(C2002 Editora: Fundação Getulio Vargas - Escola de Administração de Empresas de São Paulo.

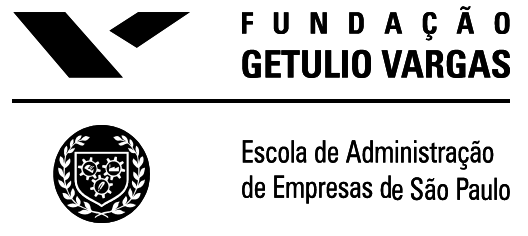




\title{
GESTÃO DA MATURIDADE DE PROCESSOS ESSENCIAIS - CONVERGÊNCIA PARA O FUTURO
}

\section{Leandro Rosa dos Santos}

Engenheiro de Qualidade da Solectron Brasil, Mestre em Engenharia de Produção pela EFEI.

E-mail: leandrorsantos@bol.com.br

Endereço: FGV - Av. Nove de Julho 2029 - Bela Vista - São Paulo - SP / CEAG Campinas

Interesses de pesquisa: Gestão por Processos

\section{RESUMO}

O presente artigo discute os dois principais modelos de gestão de negócios atualmente utilizados pelas organizações : gestão por processos e gestão por níveis de maturidade. Esta discussão tem por objetivo verificar convergências que levem a uma nova metodologia de gerenciamento que pode ser a base dos modelos de gestão que garantirão as organizações atingir desempenho superior na próxima década. A metodologia de gestão proposta é baseada na evolução e integração natural dos mais modernos modelos de gestão utilizados, visto que as demandas às organizações evoluem a partir do momento atual e rupturas bruscas nestes modelos não devem ser a base para os novos modelos que irão oferecer as organizações mecanismos para obtenção de melhores resultados. Esta análise da evolução dos modelos atuais indica grande sinergia e uma forte convergência para um modelo de gestão baseado no controle da maturidade dos processos essenciais.

\begin{abstract}
The purpose of this article is discuss the actual management models based on process and maturity levels and to propose a new methodology of management which may be used by the future organization to improve their performance. The methodology proposed of management is based on the natural evolution of the actual management models which is called on this article as Core Process Maturity Management (CPMM).
\end{abstract}

\section{PALAVRAS CHAVES}

Modelos de gestão, gestão por processos, gestão por níveis de maturidade, processos essenciais, níveis de maturidade

\section{KEY WORDS}

Management Models, Process Management, Maturity Models Management, Core Process, Maturity Levels 


\section{INTRODUÇÃO}

Quando iniciei os estudos para escrever sobre inovação em gestão deparei-me com a seguinte pergunta: Qual será o modelo de gestão que permitirá as organizações se destacarem na próxima década? É claro que responder a esta pergunta não é fácil e provavelmente não exista somente uma resposta. A gestão de uma organização, seja ela pública ou privada, com ou sem fins lucrativos é algo extremamente complexo e depende de inúmeros fatores a serem sempre considerados. Então por onde começar?

A edição especial da revista EXAME de $35^{\circ}$ aniversário trouxe no artigo "Idéias, Evoluções e Revoluções" que trata do tema inovação em gestão e que começa com a seguinte introdução :

"Nas últimas décadas, homens (muitos) e mulheres (ainda poucas) de todo mundo vêm tentando o que muitos consideram impossível: transformar a gestão dos negócios numa espécie de ciência. Nestes 35 anos, uma infinidade de teorias marcaram época, mudaram rumos, transformaram a vida das empresas e sobretudo das pessoas que fazem o mundo dos negócios. Muitas provaram-se erradas, absurdas. Algumas foram mal compreendidas. Todas, de alguma forma, fazem parte da história recente das corporações..."

Segundo o artigo da revista EXAME, os principais acontecimentos dos últimos 35 anos na área de gestão foram: na década de 70, intitulada de "BUSCA DA PRODUTIVIDADE", o artigo destaca as técnicas de análise de filas, a introdução do conceito de fluxo de caixa e o aparecimento do planejamento estratégico. Na década de 80, intitulada de "A OBSESSÃO PELA QUALIDADE", o artigo destaca o surgimento da técnica de análise de valor, a publicação do primeiro balanço social pela $\mathrm{ABB}$, a filosofia do just in time e a explosão da qualidade total. Na década de 90, intitulada de "O IMPÉRIO DO CONHECIMENTO", a reportagem cita como acontecimentos relevantes a ascensão dos grupos de trabalho, a corrida pela certificação ISO 9000, a terceirização de atividades, a re-engenharia de processos, o conceito de learning organization, o crescimento dos softwares de gestão integrada, o sistema seis sigma, o aparecimento dos softwares de CRM (Customer Relationship Management), e por fim destaca o PRM (Partner Relationship Management) como a mais nova filosofia da gestão.

Outro artigo da HAVARD BUSINESS REVIEW aponta a coordenação dos processos na cadeia de valor, pelo parceiro mais capaz, como a área com as maiores possibilidades de ganhos de produtividade atualmente. Estes aspectos de relacionamento entre uma organização, seus fornecedores e clientes, é apresentado como o próximo passo para a eficiência máxima das organizações (Hammer, 2002).

Ambos artigos indicam o relacionamento com clientes, fornecedores e parceiros como a próxima "onda" da gestão. Mas em que sentido o termo relacionamento pode ser entendido no ambiente organizacional? Numa primeira tentativa pode-se entender relacionamento como a forma pela qual as organizações interagem com o ambiente no qual estão inseridas (colaboradores, clientes, parceiros, fornecedores, governo e sociedade). Esta definição leva a uma outra pergunta importante: qual é a forma pela qual as organizações interagem? A resposta a esta pergunta parece indicar o futuro da gestão.

Antes de analisar a forma pela qual as organizações interagem é importante discutir por que a gestão se modifica e como este processo normalmente ocorre. A gestão de uma organização é o resultado das solicitações do ambiente sobre a mesma e evolui de forma a possibilitar que as necessidades solicitadas sejam atendidas, desta forma a gestão de uma organização é algo evolutivo e modifica-se em função das demandas no tempo impostas pelo ambiente à organização. Partindo deste conceito de que gestão é algo evolutivo, rupturas drásticas nos modelos atuais não devem ser a base para os modelos de 
gestão das organizações de destaque na próxima década, uma vez que as demandas sobre as organizações evoluirão a partir do momento atual. A análise das técnicas e modelos atuais de gestão provavelmente indicarão os próximos passos nesta área e conseqüentemente uma resposta a nossa pergunta sobre qual será o modelo de gestão que permitirá as organizações se destacarem na próxima década.

Voltando ao tópico anterior, podemos então tentar responder a pergunta: qual a forma pela qual as organizações interagem?

De acordo com Gonçalves(2000a), as organizações são grandes coleções de processos empresariais, os quais podem ser definidos como qualquer trabalho que seja recorrente, afete algum aspecto da capacitação da empresa (organizational capability), possa ser realizado de várias maneiras distintas com resultados diferentes em termos da contribuição que podem gerar com relação a custo, valor, serviço ou qualidade e envolva a coordenação de esforços para sua realização (Keen in Gonçalves, 2000a). A definição de processo anterior, apesar de bastante abrangente pode restringir o entendimento do termo processo empresarial, deixando subentendido que abrangência do mesmo restringe-se apenas a parte interna da organização. Então uma definição de processo organizacional/empresarial, neste momento mais apropriada para os interesses deste artigo seria "processo organizacional é a forma pela qual uma organização interage com o ambiente". Esta definição de processo permite dizer que a inovação em gestão mas esperada pelas organizações neste momento passa necessariamente sobre a modificação das formas através das quais as organizações interagem. Isto nos leva ao cerne da questão sobre inovação, indicando que qualquer inovação em gestão deve passar necessariamente pela alteração, re-estruturação ou destruição de alguns processos das organizações.

E qual será então o modelo de gestão que permitirá as organizações se destacarem na próxima década? A análise anterior pressupõe que as organizações interagem através de processos, e que a forma de gestão de uma organização é evolutiva no tempo. Portanto, uma análise das técnicas e métodos de gestão atuais provavelmente indicará uma boa resposta para esta pergunta. Como não se sabe, a priori, quais serão as demandas impostas às organizações no futuro, uma indicação para a resposta a esta pergunta somente pode ser elaborada através de um estudo das possibilidades de evolução dos modelos e técnicas atuais de gestão.

O objetivo deste artigo é propor uma possível resposta para esta pergunta (Qual será então o modelo de gestão que permitirá as organizações se destacarem na próxima década?). Para cumprir este objetivo o texto foi dividido em cinco seções. A primeira consiste nesta introdução. Na segunda discutiremos algumas técnicas e modelos atuais de gestão. Na terceira uma análise comparativa destas técnicas e modelos é apresentada, indicando pontos de convergência e sinergia. Na quarta o modelo de gestão da maturidade dos processos essenciais é proposto e discutido. Finalmente na quinta seção algumas análises e conclusões sobre as idéias deste artigo são realizadas.

\section{MODELOS DE GESTÃ̃}

Atualmente, as organizações têm utilizado uma infinidade de técnicas e modelos de gestão com o intuito de obter performance superior. A técnica de custeio baseado em atividades (Activity Based Cost ABC), o sistema de gestão da qualidade definido na nova norma ISO 9001:2000, a filosofia de gerenciamento SIX SIGMA, assim como o modelo de gestão de desenvolvimento de software CMM (Capability Maturity Model), são exemplos de metodologias de gestão que se encontram atualmente entre as mais utilizadas. 
Uma análise destas técnicas permite uma clara divisão entre duas metodologias diferentes de gestão: A gestão por processos e a gestão por níveis de maturidade. A gestão por processos tem sido utilizada como base das mais modernas técnicas de gestão do momento, trazendo conhecimento e vantagem competitiva para diversas organizações, entre as quais destacam-se: General Electric, Motorola, Honeywell (Pande et al., 2000), já o modelo de maturidade de capacidade é atualmente o principal modelo de gestão para empresas de desenvolvimento de software de todo o mundo. Clark (1997) demonstrou que a passagem de uma organização de software de um nível de maturidade para outro reduzia de 15 a $21 \%$ em média os esforços de desenvolvimento de novos produtos. Em seu trabalho Clark (1997) destaca os benefícios desta abordagem em diversas empresas, dentre as quais : IBM, Raytheon e Schlumberger.

\subsection{GESTÃO POR PROCESSOS}

De acordo com Gonçalves (2000a), a idéia de processo não é nova na administração de empresas, mas o fato de se tornar o centro da gestão é realmente novo. De uma maneira geral diversos modelos baseados em processos tem sido estabelecidos e utilizados pelas organizações e é praticamente consenso entre os estudiosos de administração, que somente empresas que conheçam e coordenem adequadamente seus processos essenciais (core process) serão capazes de sobreviver. Estes modelos de gestão por processos estão sendo aplicados em contraposição aos modelos de gestão estruturados por controle de eficiências operacionais departamentais.

A gestão por processos organizacionais difere da gestão por funções tradicional em pelo menos três pontos: emprega objetivos externos; os empregados e recursos são agrupados para produzir um trabalho completo; e a informação segue diretamente para onde é necessária, sem filtro da hierarquia (Stewart in Gonçalves : 2000a). Dentro deste conceito de obtenção de vantagem competitiva através da gestão por processos pode-se destacar três metodologias que têm sido largamente utilizadas pelas organizações: ISO 9001:2000, SIX SIGMA e ABC (Activity Based Cost).

\subsubsection{ISO 9001:2000 SISTEMAS DE GESTÃO DA QUALIDADE - REQUISITOS}

A nova norma ISO 9001:2000, publicada em dezembro de 2000, incentiva a adoção de uma "abordagem de processo" para o desenvolvimento, implementação e melhoria da eficácia de um sistema de gestão da qualidade para aumentar a satisfação do cliente pelo atendimento dos requisitos por ele especificados.

Segundo a norma, para uma organização funcionar de maneira eficaz, ela tem que identificar e gerenciar diversas atividades interligadas. Uma atividade que usa recursos e que é gerenciada de forma a possibilitar transformação de entradas em saídas pode ser considerada um processo.

Esta "abordagem de processo" indicada pela norma pode ser entendida como a aplicação de um sistema de processos em uma organização, junto com a identificação das interações entre estes processos, e sua gestão. Segundo este modelo, esta visão é vantajosa para a organização pois permite controlar de maneira contínua a ligação entre os processos individuais dentro do sistema de processos, bem como sua combinação e interação.

A norma ainda destaca que quando esta abordagem é utilizada em um sistema de gestão da qualidade, deve-se identificar a importância e os meios para o atendimento dos seguintes requisitos básicos para um processo:

- Entendimento e atendimento de requisitos do cliente; 
- Necessidade de considerar os processos em termos de valor agregado;

- Obtenção de resultados de desempenho e eficácia de processos;

- Melhoria contínua de processos baseada em medições objetivas;

.

A figura 1 apresenta o modelo de sistema de gestão da qualidade definido pela norma, de forma a assegurar o atendimento a todos os requisitos, mas não detalha nenhum processo. Os requisitos mínimos definidos pela norma são:

- Sistema de gestão da Qualidade baseado em processos

- Responsabilidade da direção

- Gestão de Recursos

- Realização de Produto/Serviço

- Medição, Análise e Melhoria

O modelo apresentado também evidencia o importante papel desempenhado pelos clientes na definição de alguns requisitos, com destaque para as entradas e saídas dos processos principais, e ainda determina que a monitorizarão da satisfação dos clientes é item fundamental deste modelo, indicando que a percepção do cliente com relação a como a organização tem atendido aos seus requisitos é essencial para o modelo de gestão proposto.

De acordo com a norma este modelo de gestão da qualidade tem capacidade de fornecer a qualquer organização meios para garantir o atendimento dos requisitos de seus clientes, assim como fornece condições para a melhoria contínua de seus processos.

Figura 1- Modelo de sistema de Gestão da Qualidade NBR ISO 9001:2000. Fonte : NBR ISO 9001:2000

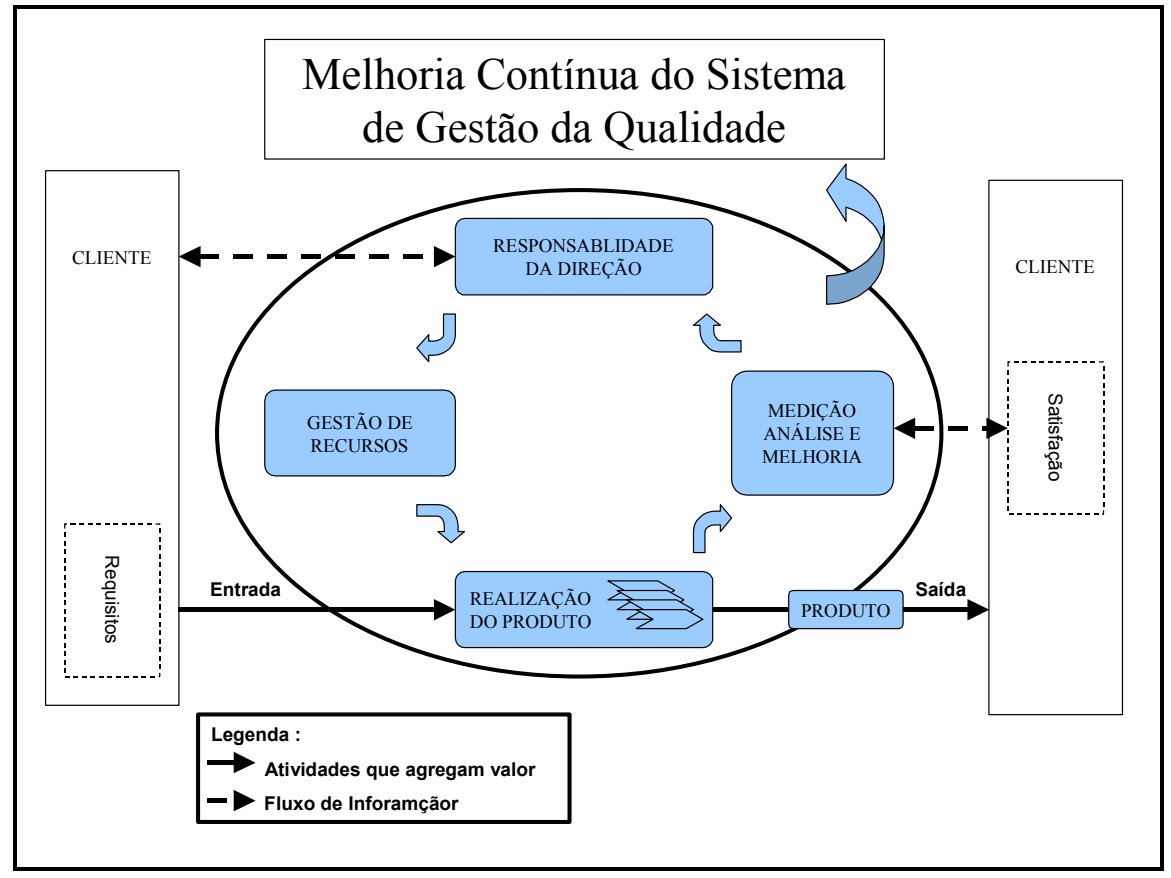

\subsubsection{SIX SIGMA}

A metodologia SIX SIGMA pode ser definida (Pande et al., 2000) como um sistema de gestão compreensível e flexível capaz de atingir, manter e maximizar o sucesso de um negócio. SIX SIGMA é 
um modelo de gestão guiado pelo perfeito entendimento das necessidades dos clientes, através da utilização disciplinada de fatos, dados e análise estatística, assim como pelo atencioso gerenciamento, melhoria e re-engenharia dos processos que sustentam o negócio.

A filosofia SIX SIGMA de gestão está baseada de uma maneira genérica em seis grandes princípios:

- Foco genuíno no Cliente

- Gerenciamento baseado em dados e fatos

- Foco nos processos, gerenciamento e melhorias

- Gerenciamento pró-ativo

- Trabalho em equipe

- Busca da perfeição e tolerância a falhas

Baseado nestes princípios, Pande define os passos a serem percorridos para a implementação da filosofia SIX SIGMA em uma organização (Pande et al., 2000):

Passo 1 - Identificação dos Processos Essenciais e dos Clientes Chaves;

Passo 2 - Definição dos requisitos dos Clientes Chaves

Passo 3 - Medição da performance atual

Passo 4 - Melhoria do Processo através do SIX SIGMA

Passo 5 - Re-engenharia dos processos através do SIX SIGMA

Passo 6 - Expansão e integração do Sistema SIX SIGMA

Segundo Pande a implementação desta filosofia de gestão numa organização permite a obtenção de desempenho superior, assim como uma base robusta para a melhoria sustentada de seu negócio (Pande et al., 2000).

\subsubsection{CUSTEIO BASEADO EM ATIVIDADES}

O custeio baseado em atividades surgiu como uma resposta da contabilidade às necessidades das modernas organizações geridas por processos. Uma vez que as estruturas organizacionais estão sendo modificadas de forma a obtenção de vantagens competitivas, novas formas de custeio foram desenvolvidas com o intuito de identificar e definir claramente onde os recursos das organizações tem sido empregados. O ABC (Activity Based Cost) é neste momento uma das mais importantes técnicas de custeio utilizada pelas organizações geridas por processos essenciais.

Segundo Martins (1996) a filosofia de custeio baseado em atividades foi concebida de forma a possibilitar a análise de custos sob duas visões:

a visão econômica do custeio, que é uma visão vertical, no sentido que apropria os custos aos objetos de custeio através das atividades realizadas em cada departamento;

a visão de aperfeiçoamento de processos, que é uma visão horizontal, no sentido de que capta os custos dos processos através das atividades realizadas;

A visão horizontal, de aperfeiçoamento de processos, reconhece que um processo é formado por um conjunto de atividades encadeadas, exercidas por muitas funções através da estrutura da empresa. Esta visão horizontal permite que os processos sejam analisados, custeados e aperfeiçoados através da melhoria de desempenho na execução das atividades. $\mathrm{O}$ ABC, nesta visão horizontal, procura custear processos, e os processos são via de regra, interdepartamentais, indo além da organização funcional. O 
ABC pode assim, ser visto como uma ferramenta de análise de fluxos de custos, e quanto mais processos interdepartamentais houver na organização, tanto maior serão os benefícios da abordagem de custeio ABC.

Em diversas organizações a utilização do modelo de custeio baseado em atividades tem sido implementada com grande sucesso para apoiar o planejamento, execução e mensuração dos custos dos processos organizacionais e seus impactos no negócio. Estas análises de custo fornecem informações mais adequadas para tomada de decisões estratégicas, uma vez que discriminam os processos essenciais das organizações e seus custos de processamento.

\subsubsection{INFLUÊNCIA DA GESTÃO POR PROCESSOS NAS ORGANIZAÇÕES}

Não seria possível discutirmos a gestão por processos sem analisarmos os principais modelos de estruturas organizacionais. A estrutura organizacional é parte fundamental de uma empresa, visto que uma estrutura inadequada colocará por terra qualquer esforço no sentido de modificação da metodologia de gestão. Desta forma, analisaremos abaixo os dois principais modelos de estruturas organizacionais:

- Estrutura Organizacional Funcional;

- Estrutura Organizacional Matricial;

Estes dois modelos constituem os dois extremos atualmente utilizados pelas empresas para gerir seus negócios. A primeira tem como característica principal a verticalização das decisões e a especialização funcional, enquanto o segundo modelo é baseado na construção de grupos de trabalho focados no negócio/produto/projeto/cliente.

O quadro abaixo mostra uma comparação das vantagens e desvantagens principais das estruturas organizacionais funcionais e matriciais.

Tabela 1 - Análise Comparativa das Estruturas Organizacionais x Funcionais.

\begin{tabular}{|c|c|c|}
\hline & Estrutura Funcional & Estrutura Matricial \\
\hline Vantagens & $\begin{array}{l}\text { - Controle Centralizado dos Resultados; } \\
\text { - Estrutura fortemente ligada a estratégia; } \\
\text { - Capacidade elevada de desenvolvimento de } \\
\text { habilidades funcionais e compet6encias de base } \\
\text { funcional; } \\
\text { - Aproveitamento superior dos efeitos da curva } \\
\text { de aprendizado/experiência associada a } \\
\text { especializaçāo funcional; } \\
\text { - Elevada eficiência operacional para } \\
\text { realizaçāo de tarefas rotineiras e repetitivas; }\end{array}$ & $\begin{array}{l}\text { - Atenção formal para cada dimensão da } \\
\text { prioridade estratégica; } \\
\text { - Cria controles e equilíbrios entre pontos de } \\
\text { vista concorrentes; } \\
\text { - Facilita a captura de afinidades estratégicas } \\
\text { baseadas funcionalmente em empresas } \\
\text { diversificadas; } \\
\text { - Promove de cisōes equilibradas na base do } \\
\text { "o que" é melhor para a empresa como um todo; } \\
\text { - Encoraja a cooperaçāo, formaçāo de } \\
\text { consenso, soluçāo de conflitos e coordenação de } \\
\text { atividades relacionadas; }\end{array}$ \\
\hline Desvantagens & $\begin{array}{l}\text { - Fragmentação excessiva dos processos } \\
\text { críticos; } \\
\text { - Pode conduzir a rivalidade interfuncional; } \\
\text { múltiplas; } \\
\text { - Furocracia da gerencia em camadas } \\
\text { nivel gerencial mais alto; } \\
\text { - Prioridade para as atividades da área } \\
\text { funcional em detrimento do negócio; } \\
\text { - Miopia funcional cria resistência a criação de } \\
\text { competências funcionais cruzadas; }\end{array}$ & $\begin{array}{l}\text { - Gerenciamento complexo; } \\
\text { - Difícil manter o equilibrio entre as linhas de } \\
\text { autoridade; } \\
\text { - Tanta autoridade compartilhada pode } \\
\text { resultar em impasse nas negociaçōes e uma } \\
\text { quantidade desproporcional de tempo consumido } \\
\text { com comunicaçōes; } \\
\text { - Dificulta a mudança rápida e decisiva devido } \\
\text { a necessidade de autorização de várias pessoas; } \\
\text { - Promove a formaçăo de burocracia } \\
\text { organizacional; }\end{array}$ \\
\hline
\end{tabular}

Fonte : Adaptado de THOMPSON, A. A., STRICKLAND, A. J., (2002)

$\mathrm{O}$ enfoque de gestão por processos tem trazido a tona dificuldades encontradas pelas empresas para se estruturarem verdadeiramente por processos, uma vez que é impossível sobrepor um processo integrado a uma organização fragmentada pelo desenho funcional tradicional. 
A tabela 1 mostra claramente a limitação dos modelos organizacionais funcionais para empresas que desejem realmente se estruturarem por processos. Para que um modelo de gestão por processos seja realmente implementado, uma mudança organizacional é imprescindível e uma organização disposta a obter os benefícios deste modelo deverá necessariamente organizar seus recursos humanos e materiais ao longo de seus processos essenciais (Gonçalves, 2000b).

\subsection{GESTÃO POR NÍVEIS DE MATURIDADE}

A gestão por níveis de maturidade surgiu no final da década de 80 através da definição do modelo de maturidade (Humprhrey, 1987a) e do Questionário de Maturidade (Humprhrey, 1987b). Este modelo foi desenvolvido pela SEI (Software Engineering Institute) como resposta a uma solicitação do departamento de defesa dos Estados Unidos sobre um método que permitisse a avaliação de seus fornecedores de software. O modelo e o questionário de maturidade evoluíram durante alguns anos de utilização e deram origem ao modelo CMM-SW (Capability Maturity Model for Software) publicado pelo SEI em 1993. Atualmente este modelo é a base da gestão do processo de desenvolvimento de software de um grande número de empresas da área de tecnologia. Apesar do modelo CMM ser aplicado atualmente na área de desenvolvimento de software, sua proposta é bastante atual e seus métodos trazem em si uma resposta para os anseios de organizações das mais diversas as áreas, pois, atualmente, os processos organizacionais são normalmente difusos e não seguem fluxos físicos, mas sim fluxos de informação os quais são a matéria prima de qualquer empresa de desenvolvimento de software. Este modelo merece especial destaque pois a visão de maturidade de processos ainda é pouco explorada nos atuais modelos de gestão por processos. O modelo CMM inclui uma rigorosa metodologia para o controle da evolução dos processos essenciais de uma organização assim como também fornece recursos para verificar se estes processos fornecem o nível de resposta esperado através da verificação do nível de maturidade.

\subsubsection{CMM - CAPABILITY MATURITY MODEL FOR SOFTWARE}

O CMM é um modelo de gestão que descreve os elementos chaves para um processo eficiente de gestão de desenvolvimento de software. Este modelo descreve os passos necessários para que uma organização evolua de um modo informal de gestão para um processo maduro, cobrindo práticas para planejamento, engenharia e gerenciamento do processo de desenvolvimento e manutenção de software. Os componentes básicos do CMM incluem:

Tabela 2 - Componentes Básicos do Modelo CMM. Fonte : PAULK et al., (1993) 


\begin{tabular}{|c|c|}
\hline Niveis de Maturidade & $\begin{array}{l}\text { Um nivel de maturidade é um platô evolutivo, bem definido, de obtenção de maturidade no processo de } \\
\text { desenvolvimento de software. O modelo CMM é estruturado em cinco niveis de maturidade. }\end{array}$ \\
\hline $\begin{array}{l}\text { Capabilidade do } \\
\text { Processo }\end{array}$ & $\begin{array}{l}\text { Capabilidade do Processo de Software define o escopo de resultados esperados e que podem ser } \\
\text { atingidos através da utilizaçáo do processo. A capabilidade do processo de software é um meio de } \\
\text { predizer de maneira adequada os resultados esperados de uma organizaçáo para um próximo proje to de } \\
\text { software }\end{array}$ \\
\hline $\begin{array}{l}\text { Areas Chaves no } \\
\text { Processo }\end{array}$ & $\begin{array}{l}\text { Cada nivel de maturidade no modelo CMM é composto de áreas chaves no processo. Cada área chave } \\
\text { no processo identifica um grupo de atividades relacionadas, que quando executadas de maneira coletiva, } \\
\text { permitem atingir um conjunto de metas que estabelecem um novo nivel de maturidade do processo de } \\
\text { desenvolvimento. }\end{array}$ \\
\hline Metas & $\begin{array}{l}\text { Metas são utilizadas para definir as práticas chaves das áreas chaves no processo e para determinar se } \\
\text { estas práticas foram adequadamente implementadas pela organizaçāo. }\end{array}$ \\
\hline Capacidades Comuns & $\begin{array}{l}\text { A implementação das práticas chaves é dividida em cinco passos comuns : (1) Definição dos } \\
\text { compromissos a realizar, (2) Habilidade de realizar, (3) Atividades realizadas, (4) Mediçăo e Análise e (5) } \\
\text { Implementação com verificaçāo. As práticas comuns são atributos que indicam se a implementação das } \\
\text { atividades das áreas chaves no processo foi efetiva, repetitiva e capaz. }\end{array}$ \\
\hline Práticas Chaves & $\begin{array}{l}\text { Cada área chave no processo é definida em termos de práticas chaves, que quando implementadas, } \\
\text { ajudam a satisfazer as metas estabelecidas para a área em questāo. As práticas chaves, descrevem a } \\
\text { infra-estrutura e as atividades que mais contribuem para a efetiva implementaçāo e inclusão das novas } \\
\text { áreas chaves no processo. }\end{array}$ \\
\hline
\end{tabular}

A utilização do modelo de gestão de desenvolvimento de software CMM prevê cinco níveis de maturidade para uma organização. Estes cinco níveis de maturidade, assim como as áreas chaves no processo para cada nível são mostradas na figura 2.

Figura 2 - Níveis de maturidade do Modelo CMM. Fonte : PAULK et al., (1993)

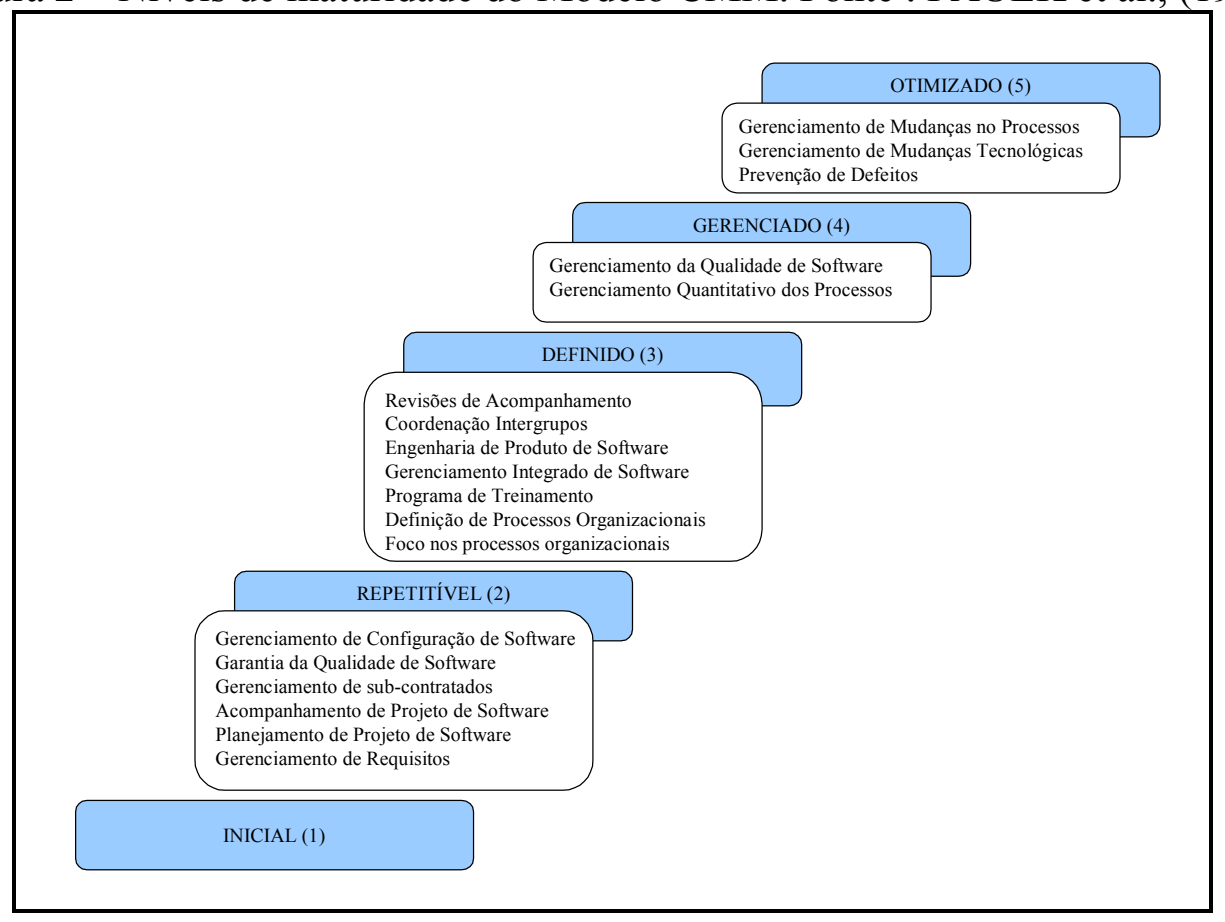

A verificação da eficiência da implementação das áreas chaves no processo para cada nível de maturidade é realizada através da auditoria das características comuns, as quais têm suas respectivas práticas chaves. A passagem de um nível de maturidade para o outro ocorre através da efetiva verificação da implementação das áreas chaves no processo para cada nível de maturidade pelas características comuns. 
Tabela 3 - Critérios de verificação de implementação de uma área chave no processo para CMM. Fonte : AMARO (2002)

\begin{tabular}{|c|c|}
\hline $\begin{array}{l}\text { 1) Definição do compromisso a } \\
\text { realizar }\end{array}$ & $\begin{array}{l}\text { Estabelecimento de políticas e responsáveis pelas áreas chaves no } \\
\text { processo }\end{array}$ \\
\hline $\begin{array}{l}\text { 2) Verificação da capacidade de } \\
\text { realizar }\end{array}$ & $\begin{array}{l}\text { Pré-requisitos, recursos e estrutura necessária para implementação } \\
\text { da área chave no processo }\end{array}$ \\
\hline $\begin{array}{l}\text { 3) Definição das atividades a } \\
\text { realizar }\end{array}$ & $\begin{array}{l}\text { Plano, procedimento, ações e documentação necessária para área } \\
\text { chave no processo }\end{array}$ \\
\hline 4) Medição e análise & $\begin{array}{l}\text { Medição e análise do processo para detectar a efetividade das } \\
\text { atividades realizadas }\end{array}$ \\
\hline $\begin{array}{l}\text { 5) Implementação } \\
\text { verificação }\end{array}$ & $\begin{array}{l}\text { Revisão, auditoria e garantia da qualidade das atividades de acordo } \\
\text { com a área chave no processo }\end{array}$ \\
\hline
\end{tabular}

A figura 3 ilustra a estrutura completa do modelo de maturidade de capacidade.

Figura 3 - Estrutura do Modelo de Maturidade de Capacidade. Fonte : PAULK et al., (1993)

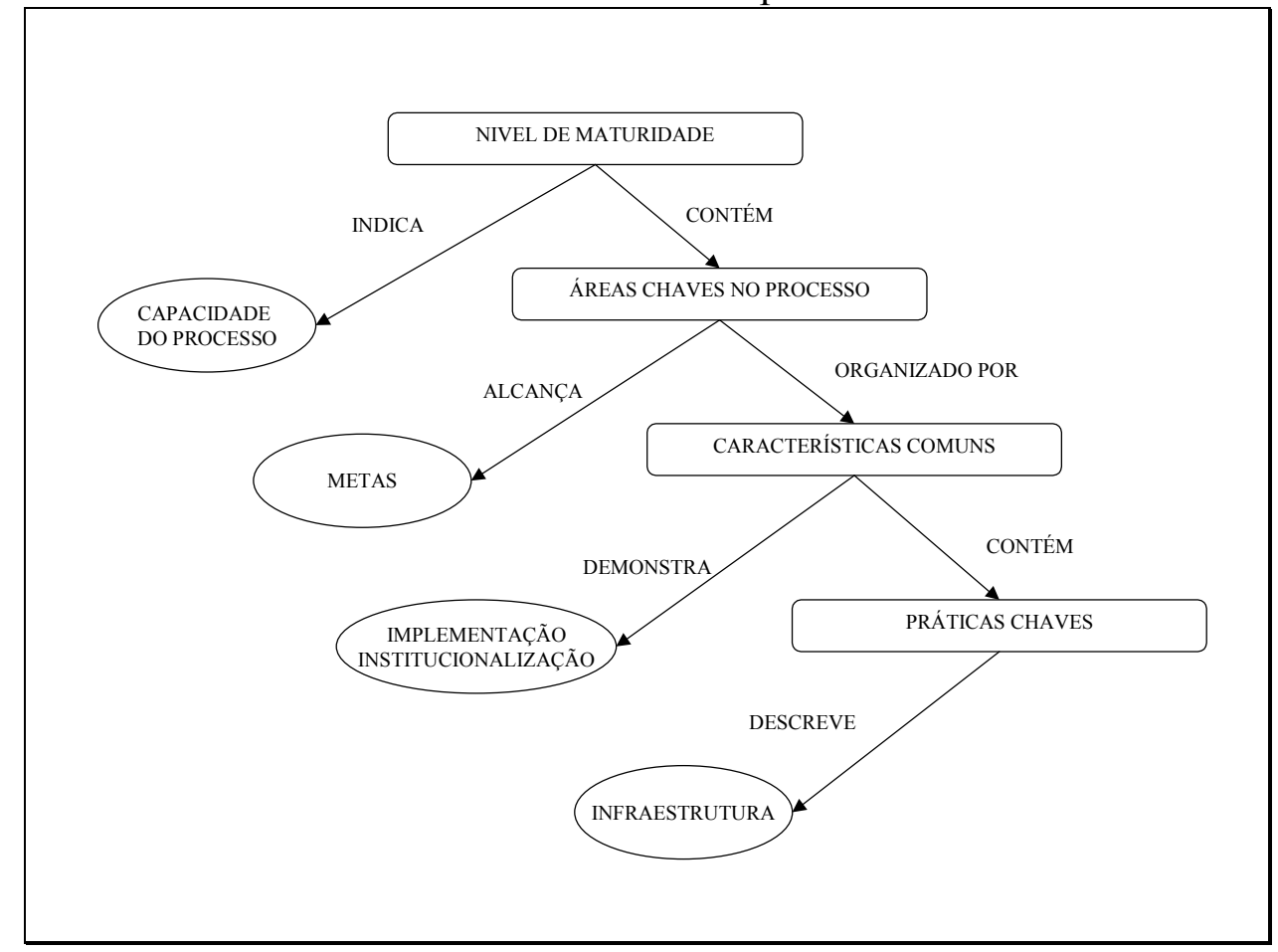

\section{ANÁLISE COMPARATIVA DOS MODELOS DE GESTÃO DISCUTIDOS}

Para propor um modelo de gestão a ser utilizado no futuro, uma análise comparativa dos modelos atuais é mostrada na tabela 4. Os requisitos analisados na tabela são destacados nos modelos como essenciais para sua efetiva implementação. 
Tabela 4 - Análise comparativas das metodologias de gestão propostas pelos modelos SIX SIGMA, ABC, CMM e NBR ISO 9001.

\begin{tabular}{|l|l|l|l|l|}
\hline Requisito & CMM & ISO 9001:2000 & SIX SIGMA & ABC \\
\hline $\begin{array}{l}\text { Liderança da Alta } \\
\text { Administração }\end{array}$ & X & X & \\
\hline Foco no Cliente & & X & X & \\
\hline Foco nos Processos de & X & X & X & X \\
\hline $\begin{array}{l}\text { Definição Niveis } \\
\text { Maturidade }\end{array}$ & X & X & X \\
\hline $\begin{array}{l}\text { Administração Baseada em } \\
\text { Fatos e Dados }\end{array}$ & $\mathrm{X}$ & $\mathrm{X}$ & $\mathrm{X}$ & \\
\hline $\begin{array}{l}\text { Metodologia de Melhoria } \\
\text { Contínua }\end{array}$ & $\mathrm{X}$ & $\mathrm{X}$ & $\mathrm{X}$ \\
\hline $\begin{array}{l}\text { Foco nos Custos/Resultados } \\
\text { dos Processos }\end{array}$ & & & \\
\hline
\end{tabular}

Da análise da tabela 4 é interessante destacarmos que independentemente da área a que se aplicam os modelos de gestão (Qualidade, Administração, Marketing, Contabilidade, Desenvolvimento) podemos notar como ponto de convergência entre todos eles a gestão dos processos essenciais. Mas apenas o modelo de maturidade de capacidade, possui um método definido para o acompanhamento da evolução dos estágios dos processos de uma organização.

\section{MODELO DE GESTÃO POR MATURIDADE DE PROCESSOS ESSENCIAIS}

Um modelo de gestão baseado em processos, os quais evoluem no tempo (ganham maturidade) é algo promissor. Este modelo baseado na maturidade dos processos essenciais é na realidade uma evolução dos modelos atuais e sua utilização pode trazer benefícios importantes, uma vez que os modelos de gestão por processos estudados, apesar de contemplarem a melhoria contínua, não definem os requisitos mínimos de maturidade para o devido controle de seu estágio evolutivo.

Esta visão de evolução do nível de maturidade de uma organização para coordenar seus processos essenciais, consiste atualmente em um dos maiores desafios das organizações que desejam implementar um modelo de gestão por processos. Gonçalves (2000b) propõem em seu artigo uma metodologia de cinco fases, de A a E (tabela 5), para orientar as organizações a se posicionarem em relação a seu nível de gerenciamento por processos. Estas fases representam de maneira geral, a mesma idéia definida pelo modelo de maturidade de capacidade, ou seja, o acompanhamento da evolução de uma organização de uma estrutura de gestão informal para uma verdadeiramente centrada em seus processos essenciais. Neste sentido as cinco fases mostradas na tabela 5 podem ser consideradas os níveis de maturidade de uma organização para a efetiva gestão de seus processos essenciais. Neste mesmo trabalho Gonçalves também propõe uma seqüência de atividades a serem seguidas para que uma organização evolua de seu estágio atual para um estágio de gestão centrado em seus processos essenciais, o que também pode ser obtido através da utilização da metodologia de níveis maturidade de capacidade.

Tabela 5 - Etapas de evolução do modelo funcional para a organização por processos. Fonte : Adaptado de Gonçalves, 2002b:14 


\begin{tabular}{|c|c|c|c|c|c|}
\hline & $\mathrm{A}$ & $\bar{B}$ & $\mathrm{C}$ & $\mathrm{D}$ & $\bar{E}$ \\
\hline $\begin{array}{l}\text { Onde } \\
\text { Estamos }\end{array}$ & $\begin{array}{l}\text { Desconhecimento } \\
\text { dos processos } \\
\text { essenciais }\end{array}$ & $\begin{array}{l}\text { Identificaçăo dos } \\
\text { processos } \\
\text { essenciais e seus } \\
\text { sub processos }\end{array}$ & $\begin{array}{l}\text { Melhoramos os } \\
\text { processos } \\
\text { essenciais }\end{array}$ & $\begin{array}{l}\text { Redistribuímos } \\
\text { nossos recursos } \\
\text { ao longo de } \\
\text { nossos processos } \\
\text { essenciais e } \\
\text { atribuímos a } \\
\text { responsabilidade a } \\
\text { um process owner }\end{array}$ & $\begin{array}{l}\text { Nossa } \\
\text { organização foi } \\
\text { desenhada } \\
\text { pela lógica dos } \\
\text { nossos } \\
\text { processos } \\
\text { essenciais }\end{array}$ \\
\hline $\begin{array}{l}\text { Até onde dá } \\
\text { para chegar } \\
\text { em termos } \\
\text { de negócio }\end{array}$ & $\begin{array}{l}\text { Chances de } \\
\text { aperfeiçoamento } \\
\text { radical limitadas }\end{array}$ & $\begin{array}{l}\text { Aperfeiçoamento } \\
\text { de gargalose } \\
\text { obtenção de } \\
\text { melhoras de } \\
\text { eficiências pontuais }\end{array}$ & $\begin{array}{l}\text { Aperfeiçoamento } \\
\text { dos processos } \\
\text { essenciais, } \\
\text { cortando as } \\
\text { atividades e } \\
\text { funçóes que năo } \\
\text { agregam valor }\end{array}$ & $\begin{array}{l}\text { Gestăo de alguns } \\
\text { processos isolados } \\
\text { e integração com } \\
\text { processos } \\
\text { auxiliares }\end{array}$ & $\begin{array}{l}\text { Gestão } \\
\text { intergrada dos } \\
\text { processos } \\
\text { essenciais }\end{array}$ \\
\hline
\end{tabular}

Para que um modelo completo de gestão da maturidade da capacidade de processos essenciais para qualquer tipo de organização possa ser efetivamente utilizado ainda serão necessários alguns anos de estudos e definições, pois os modelos de maturidade de capacidade atuais foram desenvolvidos e aplicados somente em empresas de desenvolvimento de software. No entanto sua metodologia realmente independe da área a qual será aplicado e a ampliação deste modelo para a gestão de qualquer organização pode ser a resposta para a superação das dificuldades atuais de implementação da gestão efetiva por processos nas organizações.

Figura 4 - Modelo esquemático de Gestão da Maturidade dos Processos Essenciais

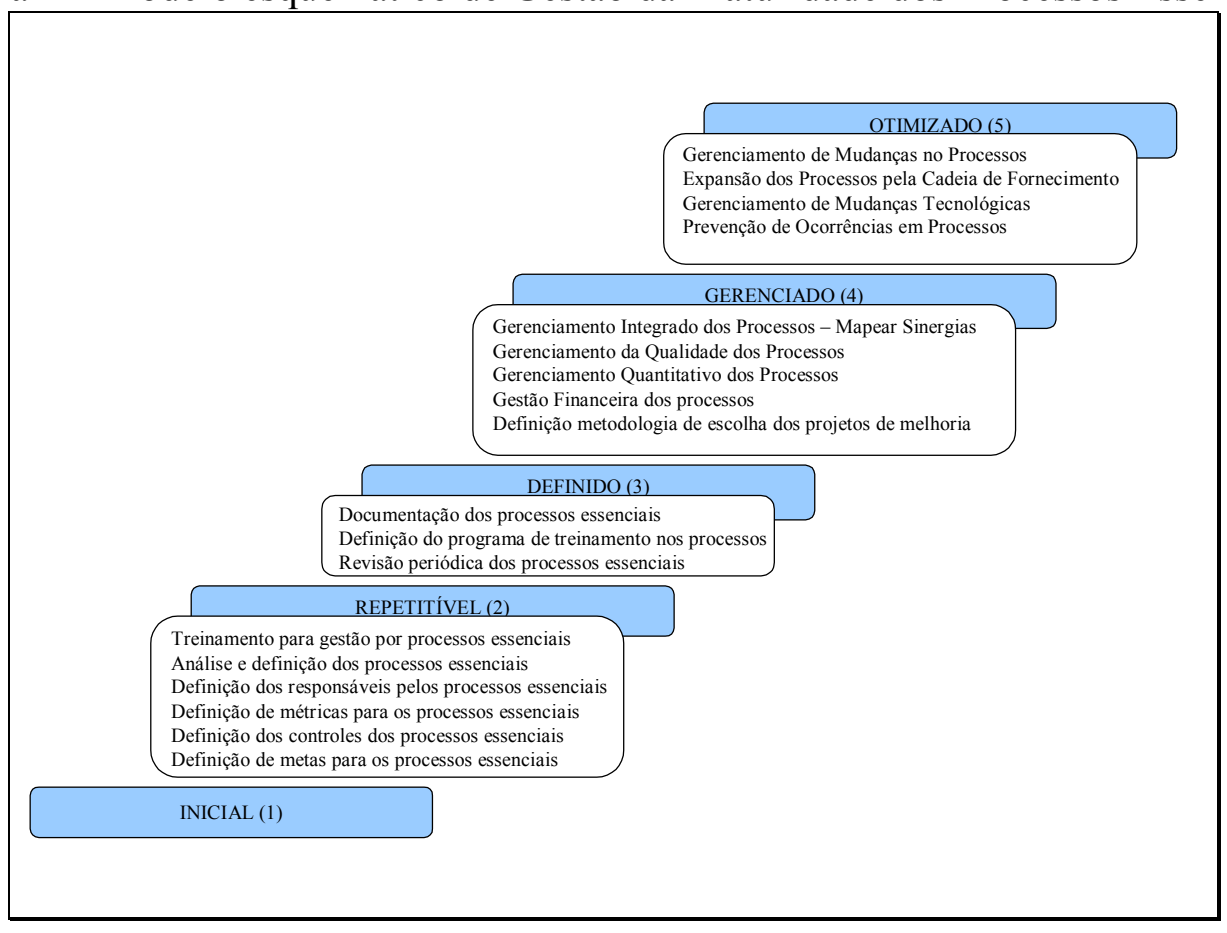

O modelo de maturidade de capacidade esquemático apresentado na figura 4, fornece uma estrutura conceitual para o aperfeiçoamento da capacidade de gerenciamento e desenvolvimento de processos organizacionais de um modo consistente e disciplinado, mas ele não garante que os processos serão adequadamente construídos ou que todos os problemas da organização serão resolvidos, apenas pode ser 
usado como base para o acompanhamento da implementação e da evolução da gestão dos processos essenciais em uma organização. É importante destacar que para cada processo essencial a organização deve identificar as áreas chaves no processo, definir as práticas chaves para estas áreas e avaliar o nível de maturidade deste processo através da aplicação da metodologia descrita nas práticas comuns, ou seja aplicar a metodologia de gestão por níveis de maturidade.

\section{CONCLUSÕES}

Este artigo procurou identificar, baseando-se na análise dos modelos atuais de gestão, uma resposta para a pergunta: Qual será o modelo de gestão que permitirá as organizações se destacarem na próxima década? A resposta a esta pergunta é sem dúvida nenhuma essencial para o sucesso das organizações, visto que a evolução do mundo atual requer cada vez mais, organizações capazes de responder rapidamente as solicitações do mercado.

A análise de quatro modelos e técnicas de gestão atualmente utilizadas com sucesso pelas organizações mostrou dois modelos de gestão predominantes: (1) baseados em processos e (2) baseados em níveis de maturidade. A análise destes modelos mostrou sinergia e não divergências o que indica que um modelo de gestão baseado nestas duas correntes deve ser o que proporcionará vantagem competitiva para as organizações na próxima década. O modelo simplificado proposto de gestão da maturidade dos processos essenciais é abrangente e contempla todos os quatro modelos estudados como um subconjunto do mesmo, colocando as características essenciais de cada modelo no corpo da metodologia. A gestão por maturidade parece ser o próximo passo dos modelos atuais de gestão por processos, uma vez que estes apesar de possuírem em muitos casos ferramentas para análise de melhoria contínua ainda carecem de maior definição sobre como verificar e acompanhar a evolução da organização no gerenciamento de seus processos.

O modelo de gestão por maturidade de processos essenciais permite aos gestores acompanhar evolutivamente o andamento da implementação dos processos essenciais uma vez que estes estarão definidos por um nível de maturidade e fornece uma boa visibilidade do estágio de implementação destes processos.

O modelo esquemático proposto indica algumas áreas chaves para cada nível de maturidade de uma organização de forma a permitir o acompanhamento evolutivo do nível de gestão da organização quando esta decide se estruturar por processos.

Este modelo assim como o modelo de maturidade de capacidade para software ainda precisa de mais desenvolvimento teórico e experimentação prática para sua verificação e desenvolvimento. Atualmente apenas poucas organizações conseguiram atingir níveis de maturidade de capacidade em desenvolvimento de softwares acima do nível 3 o que não é suficiente para garantir que o modelo seja plenamente aplicável e não necessite de modificações quando aplicável a outras organizações, mas a idéia de um modelo de gestão de negócios através da verificação da maturidade dos processos essenciais parece ser uma boa resposta para a pergunta que este artigo se propôs a responder. 


\section{REFERENCIAS BIBLIOGRÁFICAS E BIBLIOGRAFIA COMPLEMENTAR}

AMARO, A., Qualidade em TI - A Prática Explicada na Teoria, Developer's Magazine, Junho,2002;

CHIAVENATO, IDALBERTO, Introdução à Teoria Geral da Administração, Editora McGraw-Hill, $3^{\text {a }}$ Edição, SP, 1983;

CLARK, BRADFORD K., The Effects of Software Process Maturity on Software Development Effort, Dissertation, Graduate School University of Southern California, University of Southern California, 1997;

EXAME, São Paulo: Editora Abril, Abril, 2002;

GONÇALVES, JOSÉ E. LIMA, As Empresas são Grandes Coleções de Processos, RAE - Revista de Administração de Empresas, Jan/Mar. 2000a;

GONÇALVES, JOSÉ E. LIMA, Processo, Que Processo?, RAE - Revista de Administração de Empresas, Out/Dez. 2000b;

HAMMER, MICHAEL, A Empresa Supereficiente, EDIÇÃO ESPECIAL EXAME - HARVARD BUSINESS REVIEW, Abril, 2002;

HUMMPHREY, W. S., Characterizing the Software Process: A Maturity Framework, Software Engineering Institute, CMU/SEI-87-TR-11, ADA182895, June, 1987a

HUMMPHREY, W. S., Sweet, A Method for Assessing the Software Engineering Capability of Contractors, Software Engineering Institute, CMU/SEI-87-TR-23, ADA187320, September, 1987b

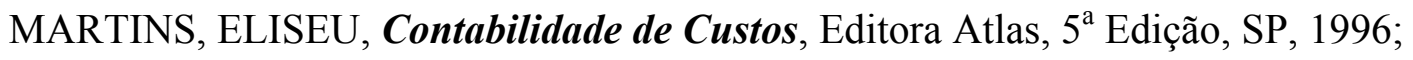

NBR ISO 9001:2000, Sistemas de Gestão da Qualidade - Requisitos, ABNT, SP, 2000;

PANDE, PETER S., NEUMAN, ROBERT P., CAVANAGH, ROLAND R., The Six Sigma Way : How GE, Motorola, and Other Top Companies Are Honing Their Performance, $1^{\circ} \mathrm{Ed}$, MacGraw-Hill, NY, 2000;

PAULK, C. MARK, CURTIS, B., CHRISSIS, M. B., WEBER, C. V., Capability Maturity Model for Software, Version 1.1, Software Engineering Institute, CMU/SEI-93-TR-024, 1993.

THOMPSON, A. A., STRICKLAND, A. J., Planejamento Estratégico : Elaboração, Implementação e Execução, $1^{\circ}$ reimpressão da Ed. De 2000, Editora Pioneira, SP, 2000. 